\title{
Application of comprehensive geophysical exploration technology in the detection of fault structure in geothermal field target area
}

\author{
Hua-an Wang ${ }^{1,2}$, Bo Xiao ${ }^{1,2}$, Xue-shan $\mathrm{Li}^{1,2}$ \\ ${ }^{1}$ Guangdong Kennuo Surverying Engineering Co., Ltd., Guangzhou 510663, China. \\ ${ }^{2}$ China Energy Engineering Group Guangdong Electric Power Design Institute Co., Ltd., Guangzhou, 510663, China.
}

\begin{abstract}
We applied CSAMT and the resistivity method based on Wenner device to the fault structure detection in a geothermal field target area, and carried out hydrogeological drilling in the geophysical anomaly area. The temperature measurement results in the well showed that the groundwater temperature is more than $50{ }^{\circ} \mathrm{C}$, which verified the effectiveness of the comprehensive geophysical method in geothermal resource exploration. The conclusions show that the resistivity method and CSAMT are suitable for the detection of thermal storage fault structures, and the comprehensive analysis method combined with the two methods can more accurately determine the plane distribution and occurrence of concealed fault structures.
\end{abstract}

\section{Introduction}

Geothermal resource is a kind of valuable clean energy, which can not only be used for heating and power generation, but also provide medical hot spring water source. The development and utilization of geothermal resources has significant economic and social benefits. Fault structure is the main channel of underground hot water migration and temperature conduction. Therefore, it is important to find out the spatial distribution characteristics of fault structures in the survey area for geothermal resources exploration, and it is of great significance to evaluate the reserves of deep geothermal resources. Drilling method and geophysical prospecting method are two kinds of commonly used geothermal resources exploration methods, the former is intuitive and accurate, but the exploration cost is high. It is mostly used for the verification of geophysical anomaly area, and the geophysical method has high efficiency which is suitable for the area detection of fault structure in geothermal field target area. The commonly used geophysical exploration methods for geothermal resources include resistivity $\operatorname{method}^{[1]}$, magnetotelluric method(MT) ${ }^{[2]}$, controllable source audio-frequency magnetotelluric method(CSAMT) ${ }^{[3-4]}$ and radon measurement method ${ }^{[5]}$. Resistivity method is one of the main technical means in the field of engineering geophysical exploration, it has strong anti-interference ability, which is commonly used in underground electrical detection within the range of several meters to tens of meters underground. MT and CSAMT detect the distribution of underground resistivity through natural or artificial electromagnetic fields, its detection depth is large and its single point measurement method has good adaptability to complex terrain and landform conditions, its disadvantage is that the received magnetic field component is easily interfered by electromagnetic field of high voltage line. Radon measurement method is a kind of radioactive detection technology which can indirectly infer the plane distribution and tendency of underground structures by measuring the radon content in the soil. However, this method can not obtain the vertical distribution characteristics of the structure, and is mostly used for the general survey of geothermal resources.

In this paper, resistivity method and CSAMT are used to detect buried faults in a geothermal field target area. Based on the analysis of abnormal characteristics of typical geophysical survey lines in the survey area, the spatial distribution characteristics of two main faults controlling heat conduction and water conduction of geothermal resources are successfully proved. The research contents of this paper can provide reference for the improvement of geothermal resources exploration technology.

\section{General geology situation of work area and layout of geophysical survey line}

The main geomorphic types of work area are hills and alluvial plains. The central area is mainly isolated residual hills with vegetation developed. The surface is slightly cut and there are sandy gullies in local bare land. Fold structures and fault structures are relatively developed in the area, but most of them are covered by the fourth system. The structure are mainly NE direction and NW direction. There are concealed rock bodies in the deep part of the

Email: xiaobo@gedi.com.cn 
survey area which provide heat source for the upper strata. Magmatic hydrothermal fluid gushes up to the shallow surface of the survey area along the fault fracture zone, which is favorable for the formation of geothermal water ore field in the survey area. The main lithology in the survey area includes carbonaceous shale, carbonaceous limestone, quartz sandstone and sandstone. When the underground rock mass has fracture structure, groundwater will be stored in the structural fracture, resulting in the resistivity near the structure being greatly reduced compared with the surrounding rock mass. This physical property difference provides the basis for electrical and electromagnetic methods to detect fault structural zone. Figure 1 shows the layout of geophysical survey lines and distribution of inferred faults in the exploration area, the geophysical survey lines are generally arranged in the northeast direction. The distance between CSAMT detection points is $20 \mathrm{~m}$. The highdensity resistivity method adopts Wenner device and the electrode distance is $10 \mathrm{~m}$.

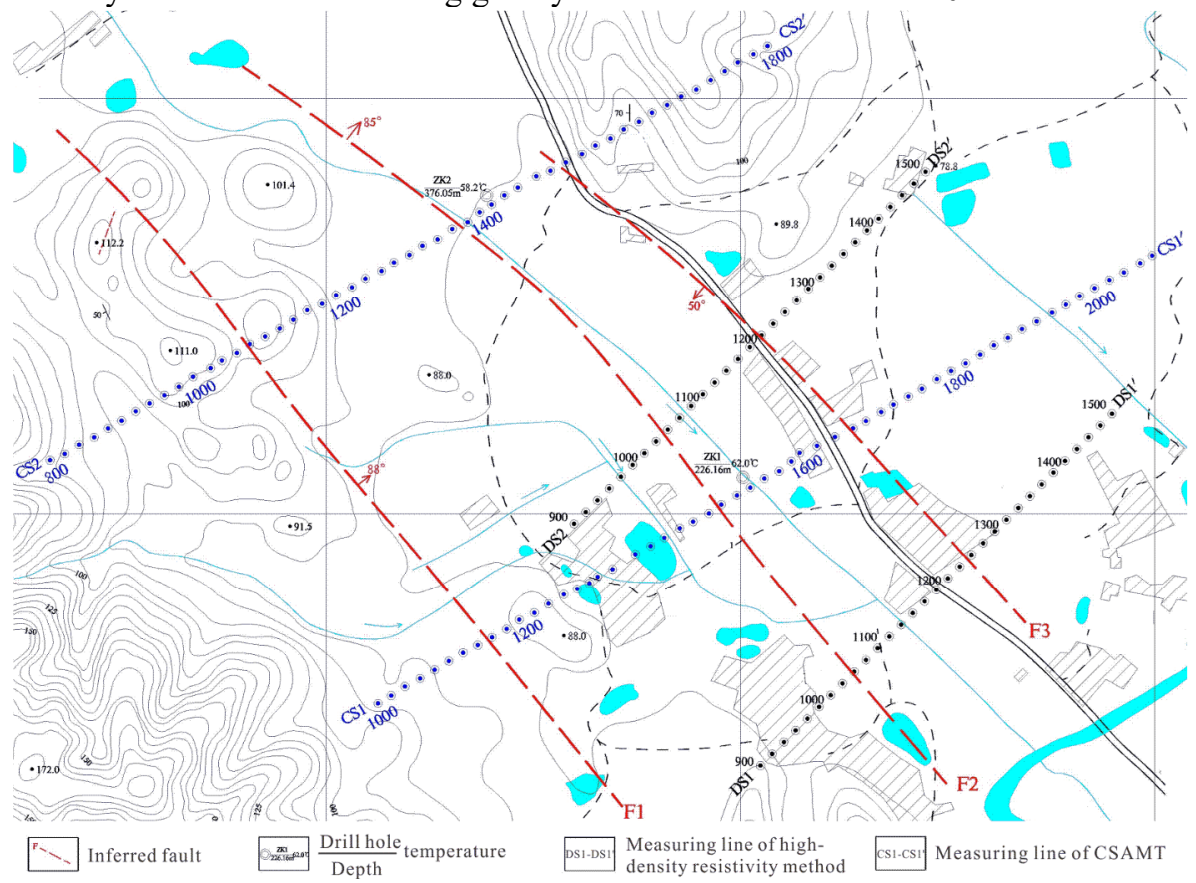

Figure 1 The layout of geophysical survey lines and distribution of inferred faults in the exploration area

\section{Results and interpretation of Geophysical method}

Figure 2 shows the detection results of high-density resistivity method of measuring line DS1-DS1'. Because of the shale and limestone in the survey area are carbonaceous and the rock mass is relatively broken, and there are many hot springs exposed on the surface and the hot spring water is highly mineralized. Therefore, the electrical method results show that the resistivity of underground media is generally low which less than 300 $\Omega \cdot \mathrm{m}$, there is a strip-shaped resistivity anomaly gradient zone with a certain extension from top to bottom near the distance of $1090 \mathrm{~m}-1210 \mathrm{~m}$. The abnormal zone inclines to the southwest with an inclination of about $50^{\circ}$ which is supposed to be caused by the shallow fault F3.

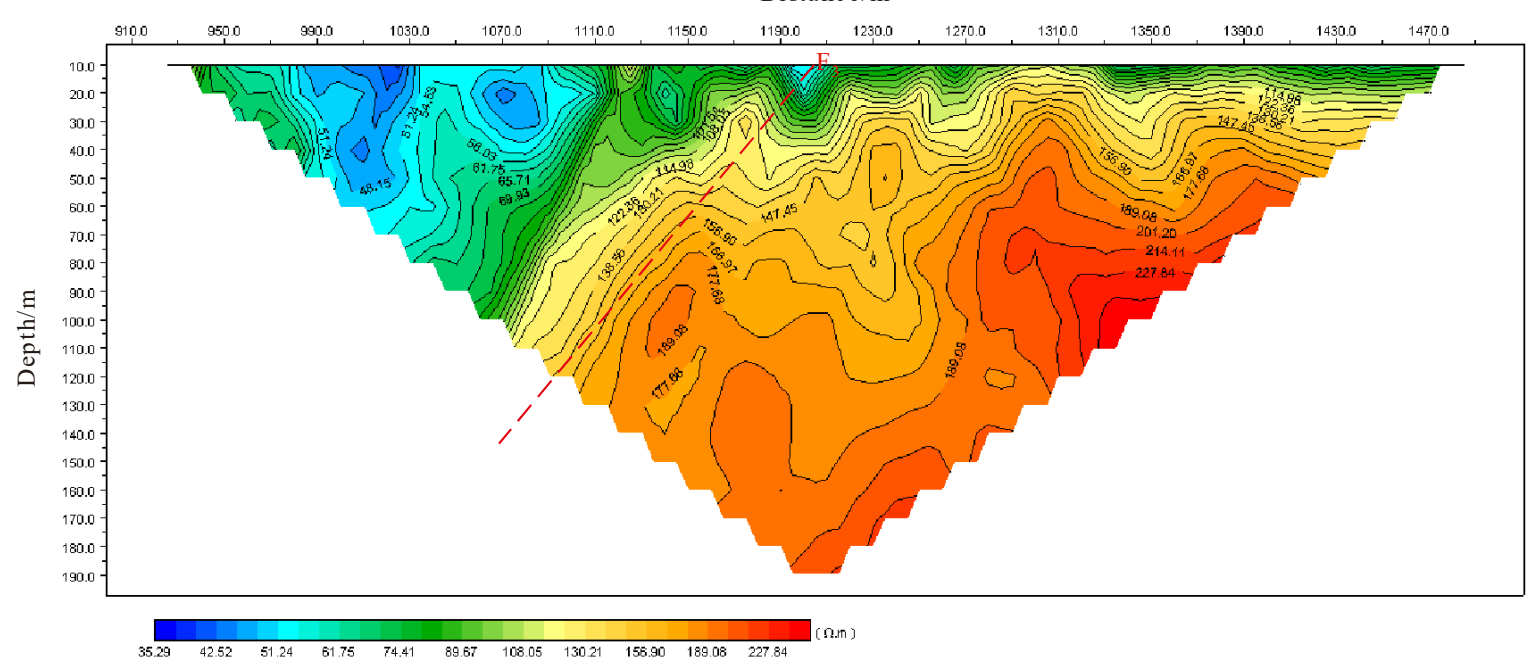

Figure 2 The detection results of high-density resistivity method of measuring line DS1-DS1' 
Figure 3 shows the detection results of high-density resistivity method of measuring line DS2-DS2', as shown in figure 3 , similar to DS1-DS1', the resistivity of underground geotechnical is less than $400 \Omega \cdot \mathrm{m}$, in which the transverse gradient of resistivity contour near the distance of $1110 \mathrm{~m}-1180 \mathrm{~m}$ changes obviously which is supposed to be caused by fault F3.

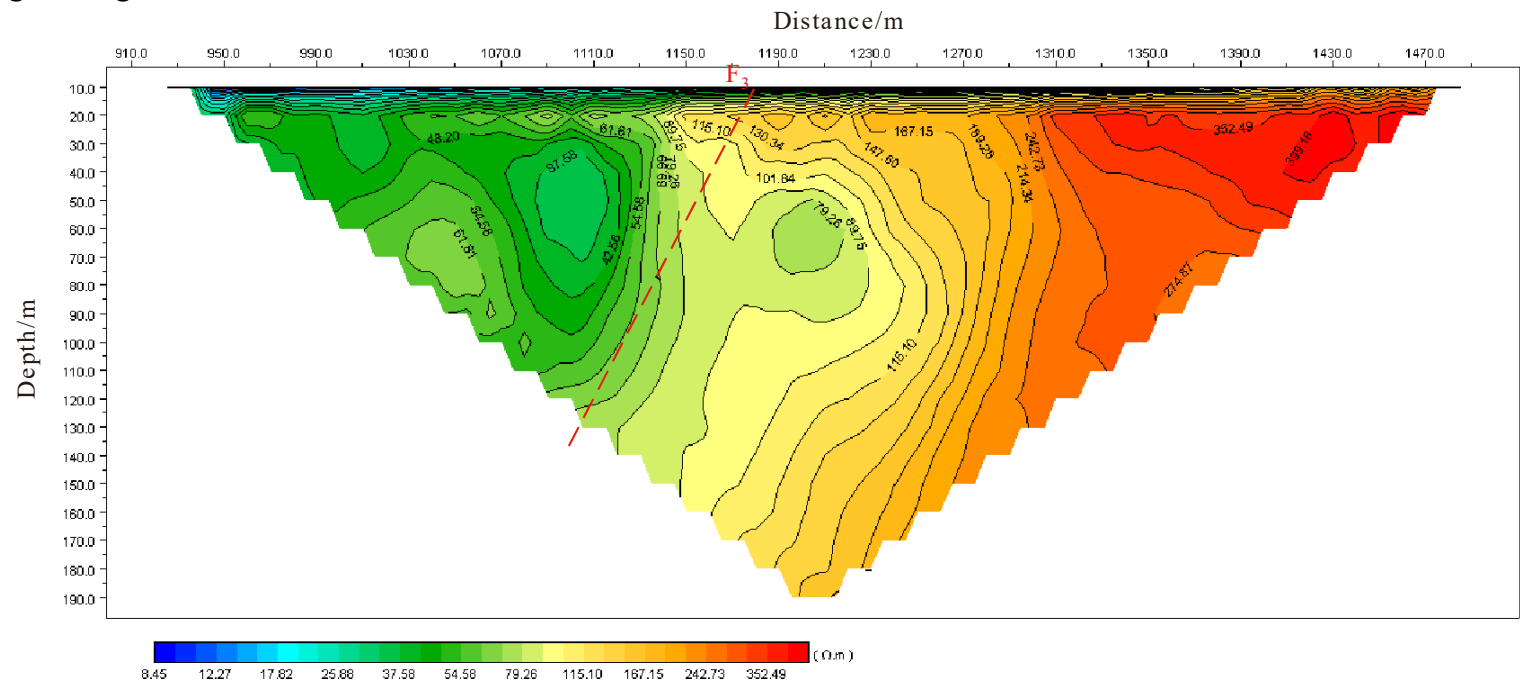

Figure 3 The detection results of high-density resistivity method of measuring line DS2-DS2'

Figure 4 is the CSAMT detection results of measuring line CS1-CS1'. As shown in figure 4, the resistivity profile generally presents a three-layer H-type electrical structure with a variation range of about $10 \Omega \cdot \mathrm{m} \sim 10000 \Omega \cdot \mathrm{m}$. Among them, the resistivity near the distance $1160 \mathrm{~m}$ is relatively low, and the contour line is depressed downward. It is inferred that there is F1 fault extending to the deep, inclining to NE direction with steep dip angle of about $88^{\circ}$. Two gradient zones of electrical property change within the distance of $1550 \mathrm{~m}-1640 \mathrm{~m}$. The resistivity of the former is relatively low resistivity anomaly due to the

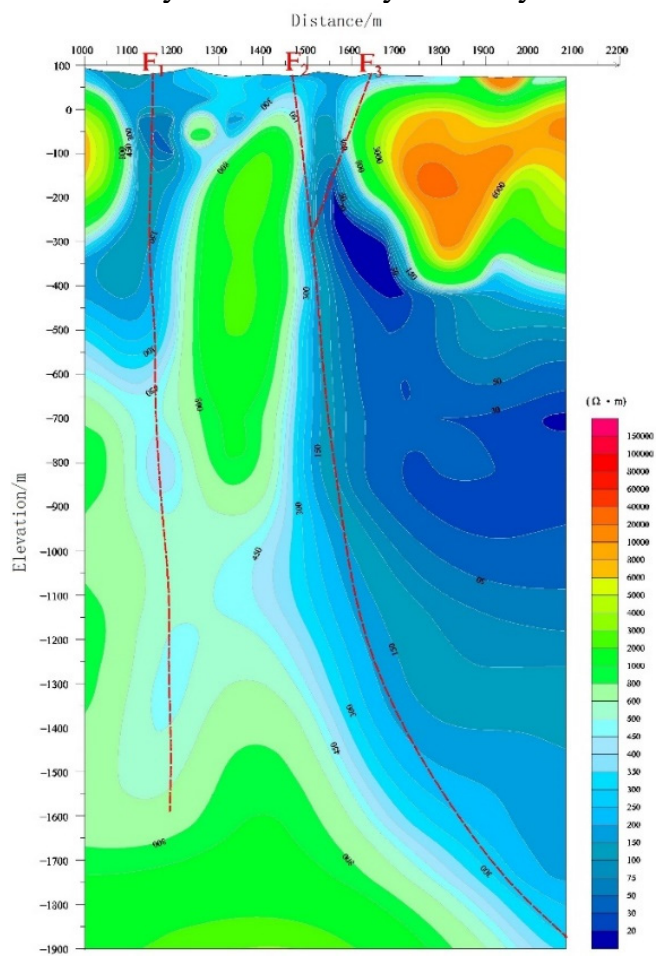

Figure 4 The CSAMT detection results of measuring line CS1-CS1' water filling fault named F2 which is inclined to the northeast, the dip angle is about $85^{\circ}$ and the latter anomaly extends to the elevation of $-150 \mathrm{~m}$, which is supposed to be the secondary fault of F2 named F3. Figure 5 is the CSAMT detection results of measuring line CS2-CS2'. As shown in figure 5, except that the resistivity value of rock mass in the area with distance $>1500 \mathrm{~m}$ and elevation $>$ $400 \mathrm{~m}$ is less than $200 \Omega \cdot \mathrm{m}$, the underground electrical structure is similar to the measuring line CS1-CS1', but the longitudinal extension depth of fault F1 becomes smaller which reaches the elevation about $-1050 \mathrm{~m}$. Distance/m

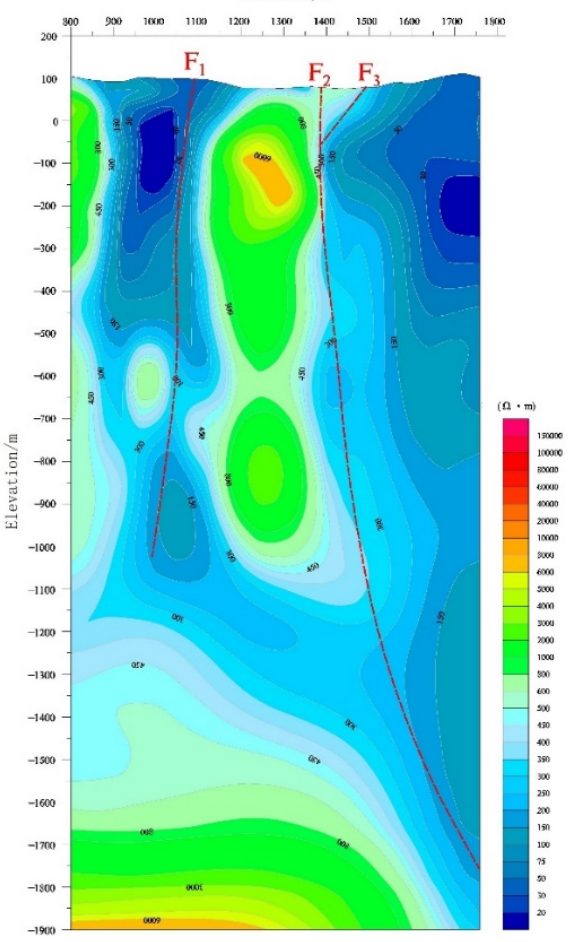

Figure 5 The CSAMT detection results of measuring line CS2- CS2' 
According to the results of high density resistivity method and CSAMT, there are three NW trending fault structures(F1, F2 and F3) exist in the survey area. Among them, F1 and F2 are deeply cut and have steep dip angles which are good thermal control structures. Fault F3, as a secondary fault structure, is connected with F2, which is a good thermal conductivity and water conducting structure. The favorable locations of underground hot water resources are fault F1, fault F2 and their contact part with fault F3, According to the geophysical exploration results, two geothermal boreholes ZK1 and ZK2 are arranged between fault F2 and fault F3.

The temperature measurement results of $\mathrm{ZK} 1$ show that the water temperature in the depth of $20 \mathrm{~m} \sim 60 \mathrm{~m}$ is mostly between $45^{\circ} \mathrm{C} \sim 52^{\circ} \mathrm{C}$ and the water temperature is unstable. It is speculated that this area is the geothermal fluid supply location and the turbulence phenomenon is obvious. The water temperature gradually drops when the depth is more than $60 \mathrm{~m}$, and the temperature is about $42^{\circ} \mathrm{C}$ to the depth of $220 \mathrm{~m}$. Temperature measurement results of ZK2 show that the water temperature in the depth $<40 \mathrm{~m}$ section is $30{ }^{\circ} \mathrm{C} \sim 45{ }^{\circ} \mathrm{C}$, the turbulence phenomenon is obvious in the depth of $40 \mathrm{~m} \sim 150 \mathrm{~m}$ and the water temperature is unstable. The water temperature in the depth of $150 \mathrm{~m} \sim 320 \mathrm{~m}$ gradually decreases about $52{ }^{\circ} \mathrm{C} \sim$ $60{ }^{\circ} \mathrm{C}$, and it is speculated that there is stable cold water pouring into the deep part. In addition, the temperature of $\mathrm{ZK} 1$ is generally higher than that of ZK2 within the depth of less than $40 \mathrm{~m}$. The reason is that the resistivity of the rock mass on the northeast side of fault F2 in measuring line CS1- CS1' is significantly higher than that in measuring line CS2-CS2', the corresponding rock mass is also relatively complete, and the underground cold water is less poured into the borehole. The pumping test and comprehensive analysis show that the recoverable geothermal fluid in the exploration area is about $1839 \mathrm{~m}^{3} / \mathrm{d}$, and the estimated thermal power of the geothermal field is 3.47 MW, which is a small-scale geothermal field. The hydrochemical type of the heat flow body in the geothermal field is $\mathrm{SO}_{4} \cdot \mathrm{HCO}_{3}-\mathrm{Na} \cdot \mathrm{Ca}$ type, which belongs to neutral to low salinity hot water. The contents of metasilicic acid, fluorine and hydrogen sulfide in the geothermal fluid all meet the concentration standard of medical mineral water.

\section{Conclusions}

The comprehensive exploration method which combining resistivity method with CSAMT can be effectively used for the exploration and reserve evaluation of underground deep geothermal resources. Among them, arranging hydrogeological drilling in geophysical anomaly area and adopting borehole temperature test is necessary. When there is no large area of high-voltage line electromagnetic interference in the exploration area, CSAMT has better detection effect on buried deep fault structure than traditional resistivity method. On both resistivity method and CSAMT section, the fault structure is characterized by resistivity isoline with large transverse variation gradient and longitudinal banded low resistivity anomaly. The resistivity value of fault zone containing geothermal water is mostly less than $500 \Omega \cdot \mathrm{m}$, and the regional resistivity value of local high salinity hot spring water can be less than $50 \Omega \cdot \mathrm{m}$.

\section{Acknowledgments}

This work was supported by the Major Projects of Applied Research and Development of Guangdong Province (2016B020242006)

\section{References}

1. Fu, G. M Huang, J. T Liu, Y Li, X. B Chen, G. Y Huang, Y (2019) Multi-electrode resistivity method and CSAMT method in geothermal exploration of Babei area in Huichang County, Jiangxi Province[J]. Geology in China, 46(4): 927-936.

2. Wang, Q Zhao, Z. P Yin, B. X Hu, F. S (2016) The Application of Magnetotelluric Sounding(MT) Method to Deep Geothermal Investigation in Plain[J]. Chinese Journal of Engineering Geophysics, 13(06):782-787.

3. Gan, F. P Lü, Y Yu, L. P Chen, Y. X (2012) The utilization of combined radon and CSAMT methods to detect underground geological structures: a case study of detection in Palian and Fapa profiles, Luxi area, western Yunnan Province[J]. Geological Bulletin of China, 31(2/3):389-395.

4. Zhang, J. P He, T.Z Wang, Y.S Jiang, Z.Z Ding, H.Z Guo, J. H (2016) Research on Geothermal Resource Exploration Technology in Granite Area within Southern Jiangsu Province[J]. Urban Geology, 11(01):30-35.

5. Miao, Q.Z Wang, G. L Xing, L. X Zhang, W Zhou, X. N Wang, W. Q (2020) Study on application of deep thermal reservoir by using geophysical and geochemical methods in the Jizhong depression zone[J]. Acta Geologica Sinica, 94(7): 2147-2156. 